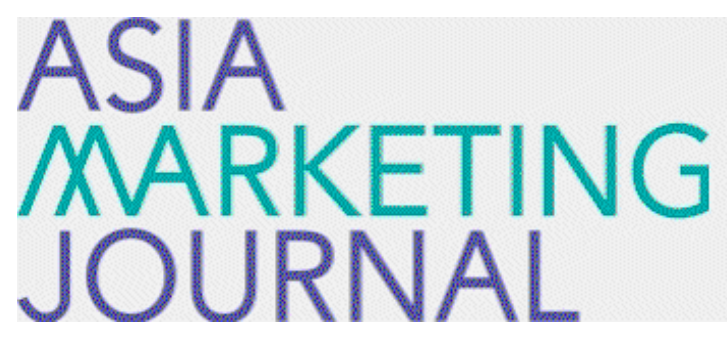

ASIA MARKETING JOURNAL

Volume 17 | Issue 3

Article 1

$10-31-2015$

\title{
The Roles of Money's Pride and Surprise Tag on the Use of Money
}

Cong Liu

Nak Hwan Choi

Follow this and additional works at: https://amj.kma.re.kr/journal

Part of the Marketing Commons

\section{Recommended Citation}

Liu, Cong and Choi, Nak Hwan (2015) "The Roles of Money's Pride and Surprise Tag on the Use of Money," Asia Marketing Journal: Vol. 17 : Iss. 3 , Article 1.

Available at: https://doi.org/10.15830/amj.2015.17.3.1

This Article is brought to you for free and open access by Asia Marketing Journal. It has been accepted for inclusion in Asia Marketing Journal by an authorized editor of Asia Marketing Journal. 


\title{
The Roles of Money's Pride and Surprise Tag on the Use of Money
}

\author{
Cong Liu* \\ Nak Hwan Choi**
}

\begin{abstract}
The present research examined the interesting but less attended effects of pride- and surprise-tagged money on consumers' spending decisions. Focusing on the unexpected money received in their daily life, we explored recipient's judgments and responses toward pride-tagged money versus surprise-tagged, and identified differences in types of recipient's consumption and spending behaviors between the pride- tagged money and the surprise-tagged money. Consumers tend to use the money associated with pride (vs. surprise) to reward their invested effort; as a result, they were more likely to buy a personal gift. Moreover, in the context of self-gift, consumers with pride-tagged money have showed a bigger positive difference between the intent to buy individual self-expressive products and the intent to buy social self-expressive products than those with surprise-tagged money. And the receipt of pride-tagged money activates motivation to express one's individual self. Consumers who have received a sum of extra money tend to add the money into the current spendable income account and broaden the array of product category. And consumers with high arousal level of surprise triggered by receiving a sum of unpredictable money because of good luck show a smaller difference between the intent to buy individual self-expressive product and the intent to buy social self-expressive product than those with low level arousal in pride. Therefore, marketers should advertise their products in the respects of individual self-expression when their customers have pride-tagged money, and should advertise their products in the respects of social self-identity when they have surprise-tagged money by winning a large sum of unpredicted money like lottery winning.
\end{abstract}

Key words: budget range, emotional accounting, pride, surprise

* Lecturer, Marketing Management School, Liaoning Technical University, Hu Ludao city, PR China (Liucong-2008@ hotmail.com)

** Professor, Dept. of Business Administration, Chonbuk National University, South Korea (cnh@jbnu.ac.kr), Corresponding Author 


\section{Introduction}

Mental accounting is a cognitive process by which people treat resources differently depending on how they are labeled and grouped (Thaler, 1999). A great amount of prior literature on mental accounting has explained how mental accounting affects consumers' spending and consumption behaviors, such as savings (Shefrin and Thaler, 1992), the effects of payment on consumption over time (Gourville and Soman, 1998), and windfall spending (Arkes et al., 1994). Such research has been used to gain insight into factors influencing consumer spending and principles used to explain mental accounting process, including categorization and mental budgeting process (Henderson and Peterson, 1992: Heath and Soll, 1996), sunk cost effect (Thaler, 1980; Arkes and Blumer, 1985), lossaversion tendency (Shefrin and Statman, 1985), and transaction coupling process (Prelec and Loewenstein, 1998).

According to affect regulation theory, individuals' perceived discrepancy between what they feel at two points in time (e.g. present feelings and future feelings as a result of the behavioral activity) plays an important affective role in guiding their behaviors (Gross, 1998). Specifically, people attempt to maintain positive feeling states and repair negative feeling states. As a result, they tend to generate different subsequent behaviors related to the current feeling states.

Past research on emotional accounting as the intensity of positive or negative feelings associated with each mental account for saving or spending (Levav and Mcgraw, 2009), has investigated that the feelings associated with money could influence consumer spending. Money can be labeled and categorized by the feelings it evokes and such an emotional label can affect consumers' subsequent spending behaviors. When the money is associated with some positive feelings (e.g., receiving a windfall typically evokes a positive experience), they tend to engage in hedonic consumption. For example, consumers are more likely to purchase hedonic products (e.g., concert tickets) with lottery prize (some positively labeled money) than those with ordinary income (O'Curry and Strahilevitz, 2001).

However, the fundamental question that arises is why consumers use the lotto or lottery prize (some unexpected extra money) versus the ordinary income to purchase self-expressive products and/or the products that they failed to afford in the ordinary consumption. Past studies only focus on the effects of general feeling states. Indeed, such a valence-based approach might by default predict different emotions of the same valence would induce similar influences on spending judgment and behaviors.

The appraisal tendency framework is considered as a basis for distinguishing the effects of specific feelings on judgment and decision-making. Distinct emotions of the same valence differ in 
their antecedent appraisals and each emotion activates a cognitive predisposition to appraise new events and objects consistent with the central-appraisal dimensions that elicit the emotion (Smith and Ellsworth, 1985). In a similar vein, Raghunathan and Pham (1999) proposed that discrete positive emotions are designed to facilitate distinct types of adaptive behaviors and social outcomes.

However, to the best of our knowledge, few studies have paid attention to the emotional accounting of specific positive feelings. According to the appraisal tendency theory, pride is associated with the tendency to perceive the self and individual's efforts as being responsible for positive events, whereas surprise is associated with the tendency to perceive others or some environmental factors as being responsible for the positive events. We can find the sources of evoking pride and those of evoking surprise differ markedly in view of the appraisal dimensions regarding responsibility and anticipated effort. Here, the present study raises the intriguing question of whether distinct emotions of the same valence, such as pride and surprise, can facilitate different influences on perception and judgment and then results in different spending behaviors.

Focusing on the unexpected money that consumers received in their daily life, we assess the money could be associated with specific positive feeling; in turn, the feeling affixed to the money may exert a substantial influence on consumers' spending behavior. In Study 1, we aim to explore recipient's judgments and responses toward two types of received money: pride-tagged money (e.g., scholarship) and surprisetagged money (e.g., lottery prize). In Study 2, we attempt to explore differences in types of recipient's consumption and spending behaviors between pride- tagged money and surprise-tagged money.

Our article will contribute to emotional accounting theory by finding that emotional accounting of two types of specific feelings of the same valence (e.g., positive feelings), such as pride and surprise, will have a significantly different influence on recipient's spending behaviors, which is presumably because specific positive emotions may activate individual's different identities that in turn motivates different consumption strategies. The second contribution of our research will be in our finding that consumers' preference for variety is affected by consumers' budget range. That is, consumers with a wide budget range for expenditure (vs. those with a narrow budget range) tend to broaden the array of product category they choose when making choice decisions. In addition, our article could contribute to the theory on affect arousal by confirming the moderating role of affect arousal level in affect regulation. Specifically, compared to those with low-level arousal of surprise, consumers with high-level arousal of surprise show a smaller difference between the intent to buy individual self-expressive product and 
the intent to buy social self-expressive product.

\section{Mental, Emotional Accounting and Consumer Behavior}

\subsection{Mental Accounting and Consumer Behavior}

Similar to organizations, consumers, typically, record, summarize, and analyze the results of transactions and other financial events in their daily life. Mental accounting is used to describe the process whereby people code, categorize and evaluate economic outcomes. Thaler (1999, p. 87) named mental accounting as the set of cognitive operations used by individuals and households to organize, evaluate, and keep track of financial activities'.

To keep track of where their money is going, and to keep spending under control, the majority of consumers have a tendency to label their resources or expenditures, and set mental budgets linked to different needs, that is, consumers often keep their spending within the budget. Consumers are more likely to spend the money grouped into "current spendable income' (e.g., a bonus) than that grouped into 'current assets' (e.g., home equity) (Shefrin and Thaler, 1992). Similarly, O’Curry (1997) has found that consumers are more likely to engage in luxury consumptions with the money won in a football pool than with an equivalent amount in overtime pay. These examples suggest that the labels associated with a sum of money can affect consumers' spending behaviors.

\subsection{Emotional Accounting and Consumer Behavior}

On a basis of emotional accounting research, money can be labeled and categorized by the feeling it evokes. The feeling associated with the money is named as money's "affective tag" (Levav and Mcgraw, 2009). The valence (positive and negative) and intensity of such feelings can affect consumers' spending behaviors. In short, the emotional accounting categorized the money by the feeling it evokes, and the emotional label can lead to a substantial influence on recipients' spending behaviors.

The receipt of a windfall (e.g., unexpected monetary gains), typically, involves a positive experience, which promotes the windfall to be used more readily and frivolously (Epley and Gneezy, 2007). For example, O’Curry (1997) demonstrates that money associated with positive feelings is less predictable source of income and thus is more likely to be spent on hedonic options, such as concert tickets, extravagant meals, and other forms of entertainment. In contrast, money received in a contentious life insurance settlement may be labeled as "negative money" because it is always associated with the pain of battling the insurance company. 
Consumers attempt to seek products (e.g., utilitarian products) to reduce the negativity associated with their received money (Levav and Mcgraw, 2009).

\subsection{The Classification of Pride- and Surprise-tagged Money}

Smith and Ellsworth (1985) identified six cognitive dimensions that can best define the patterns of appraisal underlying different emotions, namely, certainty, pleasantness, attentional activity, control, anticipated effort, and responsibility. Each emotion differs in these six dimensions of appraisal and can be defined by its central dimensions which characterize its core meaning or theme (Lazarus, 1991). According to the appraisal tendency theory, "emotions can not only arise from but can trigger an implicit cognitive predisposition to appraise future events in line with the central appraisal dimensions that characterize the emotion' (Han, Lerner, and Keltner, 2007, p. 160).

Focusing on pride and surprise, in this research, we argue these two positive feelings could exert significantly different impacts on subsequent motivation to pursue a task and subsequently prompt different types of judgment and choice behavior though both feelings have same positive valence. In accord with the appraisal-tendency view, pride and surprise differ markedly in their appraisal themes, such as responsibility, certainty, and invested efforts. In particular, pride is a positively valenced emotion evoked in response to a certain outcome; it is associated with the tendency to consider the self per se and the individual effort as being responsible for positive events. That is, when experiencing pride, the self is the cause of a positive outcome, which is consistent with the arguments that a positive outcome or success which is attributed to individual's own great efforts can trigger feelings of pride (Faure and Mick, 1993). In contrast, surprise is characterized by a neutral and short-lived emotion that is induced by unexpected events (Izard, 1977). Similarly, Reisenzein, Meyer, and Schützwohl (1996) suggest that surprise is caused by cognitive appraisal processes (typically thought to consist in the appraisal of unexpectedness). In addition, surprise is a positively valenced emotion evoked in response to an uncertain outcome; it is associated with the tendency to perceive others and relatively less individual efforts as being responsible for the positive events. In other words, people could experience feelings of surprise when a positive outcome is caused by someone else and/or something else (e.g., fate). $\langle$ Table 1〉 shows the differences between pride and surprise in three central appraisal dimensions.

In this research, a sum of money received through individuals' great efforts and attainment of accomplishment is labeled as "pride-tagged money" (e.g., scholarship), whereas the money received through winning a big lottery prize is labeled as "surprise-tagged money". 
$\langle$ Table 1〉 The Differences Between Pride and Surprise in Their Central Appraisal Dimensions

\begin{tabular}{|l|c|c|c|}
\hline Feelings & Rimensions & Invested Efforts & Certainty \\
\hline Pride & Self & High & High \\
\hline Surprise & Others & Low & Low \\
\hline
\end{tabular}

\section{Pride-tagged and Surprise- tagged Money and Budget Range}

\subsection{Pride- and Surprise-tagged Money and Individual Self-Consciousness}

As we mentioned above, pride is characterized by appraisal themes of achieving a positive outcome or success through individual's great efforts (Faure and Mick, 1993) and, thus, accompanies the action tendencies to direct attention to the self per se. For example, scholarship can be viewed as the money labeled by pride, because it reflects a student's invested great effort in his or her study. When receiving such pride-tagged money, students often consider that the individual self per se plays a significant role in receiving the scholarship, see their individual self as the center of attention.

Focusing attention on the individual self could help promote personal self-consciousness. Han et al. (2007) suggest that individual appraisal dimensions of specific feelings can drive consumers' own thoughts. Pride involves increased self-awareness and further causes people to focus their attention inward. Therefore, we pre- dict, consumers who have experienced pride about a sum of money tend to direct more attention to their individual self and emphasize the essential roles of the self, which might induce thought or consciousness focused on the individual or personal self (e.g., thoughts relating to the self as a distinct individual). In contrast, surprise is characterized by appraisals of receiving a positive outcome unexpectedly and, thus, accompanies the action tendencies to direct attention to others rather than the personal self. Compared to the money received through individual hard work, an equivalent amount that is won in a lottery may be perceived as unexpected, less serious, costless, and less related to the individual efforts. Hypothesis is expressed as follows:

H1: Pride-tagged money can promote more personal self-consciousness than surprisetagged money.

\subsection{Pride- and Surprise-tagged Money and Savings and/or Spending}

Money, as a medium of exchange or standard of payment, functions as a way to allow consumers to acquire or purchase items needed 
for everyday living, a higher quality of life, and to increase the ability to help others and society in general. People can express their security, power, love, and freedom by money. Different consumers treat money in different ways. Some may spend money to purchase what they need or want now, while others might be more likely to save money. People do not treat all values as fungible or translatable each other on a dollar metric (Thaler, 1999). This article proposes the perceived value of a certain fund should depend on how it is labeled by feelings money-recipients have experienced.

Weiss and Johar (2013) have found that consumers with a higher level of personal selfconsciousness tend to classify the product as part of himself or herself, and thus judge traits of that product in assimilation to how they evaluate the "self" on these traits. For instance, if a consumer temporally feels more creative, he or she would judge a product owned as being more creative when they are under high self-consciousness condition. Similarly, we predict consumers who temporally feel proud of themselves because of receiving a sum of money through individual efforts tend to judge the received money as being proud, which further induces the subjective perception that the money labeled by pride is more valuable relative to its actual value.

People tend to put more values on a certain kind of monetary gains than other kinds of monetary gains. For instance, students often consider the scholarship as being more valuable than their pocket money given by their parents. In contrast, indeed, the unexpected monetary gains are often viewed as less valuable than the money earned hard, thus consumers spend the money received unexpectedly (vs. regular base salary) more readily and frivolously (Epley and Gneezy, 2007). Our hypothesis is expressed as follows:

\section{H2: The perceived psychological value of pride-tagged money is greater than that of surprise-tagged money.}

Individuals experience psychological pressure about costs (e.g., money, time, and effort) before paying for something (Gourville and Soman, 1998). When consumers decide to buy something or trading money for some object, they tend to code the acquisition of the product as a gain and the forgone money as a loss. Paying money associated with individual effort for some object might evoke a high level of sunk-cost (effort) pressure and more immediate pain of paying. In contrast, people who have received a sum of unexpected money are becoming riskseeking and may find it less painful to pay for when making purchase-decisions, in part because the money is often considered as being effortless and less important.

Moreover, how a sum of money is acquired could affect consumers' decisions about saving or spending of the money. For example, if a 
person invests a lot of resources (e.g. time, money, and effort) for receiving an object, he or she tends to psychologically justify that kind of investment and the object as part of his or her extended self. McGraw, Tetlock, and Kristel (2003) have showed that money received from a simple purchases (e.g., a special prize) is likely to be placed in a current income account and spent easily and impulsively; in contrast, money received from a particular relational source (e.g., parent, teacher, or friend) is more likely to be treated with increasing responsibility and saved in a current asset account. Accordingly, we predict consumers may be less likely to spend pride-tagged money because forgoing the money received through great individual efforts can be viewed as a big loss, which further leads them to be careful in spending the money. In short, consumers might be more willing to save the money associated with the personal self. Our hypothesis is expressed as follows:

H3: Consumers with pride-tagged money tend to save a greater amount of the money than those with surprise-tagged money.

\subsection{Pride- and Surprise-tagged Money and Self-expressive Motive}

Individual's self-expressive motive, one of the basic motivations human beings have, is developed on a basis of the needs to assert one's in- dependence and distinctiveness (Chernev, Hamilton, and Gal, 2011). Pride, as a self-relevant emotion, involves the individual's inner state or attributes as a primary referent, to the exclusion of others, and also fosters an independent (vs. interdependent) self (Aaker and Williams, 1998). The feelings of pride and pleasure could lead one's self-expressive motive become salient (Aaker, 1999). For instance, when receiving a scholarship (pride-tagged money), a student may begin to emphasize the personal importance and direct attention to the personal self, as a result, he or she might begin to care about being unique in his or her particular personally important domains (e.g., study).

The functional theory of emotions assumes that each emotion is composed of motivational action tendencies and can facilitate goal pursuit (Frijda, 2005; Keltner, Haidt, and Shiota, 2006). In a similar vein, the appraisal tendency framework posits that each feeling carries with it motivational properties that play a significant role in subsequent judgments and decisions (Lerner and Keltne, 2000). Therefore, we predict the receipt of pride-tagged money could increase the likelihood of expressing one's personal or individual self, and further generate behaviors related to expressing the important aspect of the self. Our hypothesis is expressed as follows:

H4: Consumers are more motivated to $\mathrm{ex}^{-}$ press the individual self when choosing products in exchange of pride-tagged 
money than in exchange of surprisetagged money.

\subsection{Pride- and Surprise-tagged Money and Budget Range and Variety- Seeking Behavior}

Budget range is considered as a control device to govern expenditures (Thaler, 1980). Consumers often fix an upper and lower limit of their budget for consuming each product category in order to prevent overspending. Similarly, Park and Kim (2005) have shown that the budget range serves to moderate expenditures on a certain product category, such that varying the budget range can change cognitive focus of the consumers who start off in an adding or a deleting mode. Consumers under narrow budget range condition tend to focus on expenditurerelated factors and engage in specific financial activities. On the other hand, under a wide budget range condition, consumers feel they have sufficient money and thus tend to cover almost all of the expenditures for products. Consumers who have received surprise-tagged money might consider fate or luck being responsible for receiving such money and thus might upper the limit of their budget and spend the money in a broad way. On the other side, consumers with pride-tagged money might use a control device to govern their expenditures because they often experience high sunk-cost (e.g., effort) pressure when spending the money earned hard.
Variety-seeking often happens when consumers feel uncertain about future preference at the time of consumption due to the unknown changes in states of mind and tastes (Simonson, 1990). People who simultaneously choose multiple items tend to diversify their choice set when making purchases in a category (e.g., Simonson, 1990; Goukens, Dewitte, and Warlop, 2009). For instance, to satisfy their need for novelty and change, consumers are likely to choose yogurt with different flavors, such as kiwi, strawberry, and blueberry flavored yogurt. However, this article predicts the selection of variety is constrained by consumers' budget range. The wider the budget range, the more likely varietyseeking behaviors are to take place.

Specifically, as the budget range of surprisetagged money broadens, consumers are inclined to increase preference for variety and accept a broader array of product category they choose when making purchase decisions. In contrast, given that consumers who have experienced pride are motivated to express their personal self, they are likely to choose products related to selfexpression when making choice decisions, which further results in a reduction of the numbers of product category they choose. Our hypothesis is expressed as follows:

H5a: The expenditure budget range of consumers with surprise-tagged money is wider than that of consumers with pride-tagged money. 
H5b: Consumers with surprise-tagged money are more likely to increase their scopes of product category than those with pride-tagged money when making choice decisions.

\section{Study 1:}

The primary objective of Study 1 is to explore consumers' judgments and responses toward two types of received money: pride-tagged money (e.g., scholarship) and surprise-tagged money (e.g., lottery prize).

\subsection{Method}

\subsubsection{Participants and Method}

We employed a questionnaire survey methodology for our data collection. There are two kinds of questionnaire in this survey that share a common structure; one kind of questionnaire was developed for a condition in which a sum of money is received under circumstance that evokes feelings of pride (pride-tagged money) and the other one was developed for a condition in which a sum of money is received under circumstance that evokes feelings of surprise (surprise-tagged money). We translated the original questions written in English into Korean following a standard back-translation procedure where, we found, there was no problem

Two marketing classes of large university in South Korea were used as experimental group. Forty five students of each class participated in this empirical study in exchange for a piece of chocolate pie and a highlighter. 45 questionnaires for each condition (class) were randomly delivered to, and collected from, the students. 5 questionnaires (4 in pride-tagged money condition and 1 in surprise-tagged money condition) were excluded for the reason of invalid completion. As a result, we used 85 valid samples that account for $94.4 \%$ of the questionnaires delivered.

\subsubsection{Procedure}

To manipulate pride-tagged money, we told participants to read a scenario with some pictures and to imagine that they have invested great efforts into study and have received a scholarship that amounts $W 1,500,000$ (about US \$1,500) whereas participants in the surprisetagged money condition, were told to imagine that they have bought a lottery ticket on the way home by chance and have received a prize of $W 1,500,000$ in a local lottery station. The Appendix A presents the text of the scenario for each condition.

Pretest under each scenario condition was conducted to check whether the scenario for pride (surprise) - tagged money leads to the place 
of inducing pride (surprise). Twenty undergraduate students were assigned to the pretest on the scenario for pride - tagged money, and twenty undergraduate students were also assigned to the pretest on the scenario for surprise - tagged money. Participants exposed to the scholarship (lottery) scenario expressed such emotion as pride, efforts, self-satisfaction, selfworth (surprise, lucky, amazed) to the question, 'what kind of emotion do you feel to the scenario which you read?' Therefore the scenario manipulation was successful.

Main tests were conducted. After being exposed to the scenario, participants in each condition (pride- and surprise-tagged money condition) were told to complete some emotion measures designed to assess the presence of a kind of feeling about the money. We expect that participants in the pride (surprise)-tagged money condition experience more feelings of pride (surprise) than those in the surprise (pride)tagged money condition.

Following the emotion measures, all the participants were told to complete a survey containing individual and social self-consciousness scales. Following the manipulation of individual/ social self-consciousness, we asked participants to indicate their perceived psychological value of the received money on a seven-point scale
(1= "less than, $\$ 1,500,000 "$ and $7=$ "more than $W 1,500,000 ")$. Moreover, participants were asked to indicate how they would do with the received money on a seven point scale $(1=$ "to buy something," and $7=$ "to save the money"); if they want to save the received money, we asked them to indicate how much they would like to save, and if they want to use the money to buy something, we asked them to indicate how much they would like to spend.

On completion of the saving/consumption task, participants in both conditions were told to complete self-expressive motive measures. And then we informed them to complete a survey used to measure the budget range for expenditure. In order to manipulate variety-seeking behaviors, participants in both conditions were told to make a list of what they would buy by using the received money. We expect that participants in the surprise-tagged money condition will list more types of product ${ }^{1)}$ than those in the pride-tagged money condition because they could set relatively wide budget range in the mind. That is, the number of products participants would like to buy varies as a function of their budget range for expenditure.

1) In the current research, in order to measure consumers' variety-seeking tendency, we will compute the number of participants' listed products, that is, if the participants select more products based on product categories, they are more likely to prefer variety-seeking. For example, after receiving a sum of money, we expect that participants will buy fashion clothes, books, computers, etc. 


\subsection{Measures}

\subsubsection{Pride and Surprise}

After being exposed to the scenario, whether participants have experienced pride about the received money was measured on a 3-item scale $(1=$ not at all, $7=$ very much $)$ consisting of pride-related words (proud, self-respect, and self-worth; $\alpha=$.947) (Wilcox, Kramer, and Sen, 2011; Richins, 1997). Similarly, we used three surprise-related emotions (surprised, amazed, astonished; $\alpha=$.851) to measure whether participants have experienced surprise about the received money by using a 7-point scale anchored by "not at all (1) - very much (7)”.

\subsubsection{Individual-Self and Social-Self Consciousness}

Self-consciousness involves individuals' attention directed inward or outward. Private selfconsciousness involves attending to one's inner thoughts and feelings, whereas public self-consciousness refers to a general awareness of the self as a social object that has an effect on others (Fenigstein, Scheier, and Buss, 1975). Private and public self-consciousness can be operationalized through measuring the tendency to attend to private and public aspects of the self. Pride involves increased self-awareness; it could cause people to focus their at- tention inward. Thus, this research referred to the items used to measure private and public self-awareness to measure individual- and social-self consciousness. The individual self-consciousness scale consists of 10 items ( $\alpha=$ .891), whereas the social version consists of 7 items $(\alpha=.918)$ (Fenigstein, Scheier, and Buss, 1975), both of which use a 7-point scale anchored by "not at all (1) - very much (7)" (See Appendix B).

\subsubsection{Individual Self-Expressive Motive}

We referred to five items to measure participants' activated individual self-expressive motive in terms of expressing the personal selfvalue anchored by "strongest disagree (1) strongest agree (7)" consisting of five selfexpression-related words (self-respect, sense of accomplishment, self-fulfillment, security, being well-respected; $\alpha=.917$ ) (Shim and Eastlick, 1998).

\subsubsection{Budget Range}

We referred to three items to measure participants' budget range for expenditure anchored by "not at all (1) - very much (7)". The items include "I would like to spend the received money in purchasing some hedonic products that I could not afford in the ordinary consumption," "I would like to increase my scopes of product category and to purchase various 
types of products by using the received money," "I would like to spend the received money in purchasing more products with various options" $(\alpha=.714)$.

\subsection{Results of Empirical Study 1}

\subsubsection{Confound and Manipulation Check}

To minimize the potential confound, three steps were taken. Firstly, we referred to three items to measure the attention that participants paid to reading the scenario in both prideand surprise-tagged money conditions on a seven-point scale $(1=$ not at all, $7=$ very much). The items include "I paid attention to the above scenario," "I am interested in the above scenario," and "I am committed to the above scenario". The results of ANOVA by summed and averaged values showed that there was no attention difference between prideand surprise-tagged money conditions $\left(\mathrm{M}_{\mathrm{p}}=5.67\right.$, $\left.\mathrm{M}_{\mathrm{s}}=5.48, \mathrm{~F}(1,83)=.624, \mathrm{p}>.05\right)$.

Secondly, in order to verify whether participants in the pride- (surprise-) tagged money condition have experienced more feelings of pride (surprise) about the received extra money than participants in the surprise - (pride -) tagged money condition, we made new scale $(\mathrm{P}-\mathrm{S})$ producing the scale range from 6 to -6 by subtracting the averaged value of the surpriserelated item ratings $(\mathrm{S})$ from the averaged value of the pride-related item ratings $(P)$ for each participant. This yields a summary measure of feeling, P-S; higher numbers indicate greater pride than surprise, whereas lower numbers indicate greater surprise than pride.

The results of ANOVA showed that our affect manipulation was effective. The summary measure of feeling, P-S, was indeed greater in the pride-tagged money condition $(\mathrm{M}=1.4634)$ than in the surprise-tagged money condition $(\mathrm{M}=-2.8561)(\mathrm{F}(1,83)=148.008, \mathrm{p}<.001)$. That is, participants reported experiencing more feelings of pride (surprise) about the money in the pride (surprise)-tagged money condition.

In order to check whether pride and surprise are associated with different appraisal dimensions, thirdly, we referred to two items on a sevenpoint scale $(1=$ good luck/others or environmental factors, $7=$ myself $/$ my effort). One way ANOVA showed that participants in the pride-tagged money condition $(\mathrm{M}=5.7561)$ considered the individual self was responsible for receiving the scholarship, whereas people in the surprise-tagged money condition $(\mathrm{M}=1.7727)$ considered good luck was responsible for receiving the lottery prize $(\mathrm{F}(1,84)=175.474$, $\mathrm{p}<.001)$. Similarly, participants in the pridetagged money condition $(\mathrm{M}=5.5610)$ considered individual effort was responsible for receiving the scholarship, whereas people in the surprise-tagged money condition $(\mathrm{M}=2.6591)$ considered others or environmental factors were responsible for getting the lotto prize $(\mathrm{F}(1,83)$ $=68.051, \mathrm{p}<.001)$. 


\subsubsection{Testing Hypotheses}

In an effort to test H1, we carried out a one-way ANOVA. The analysis results showed that participants in the pride-tagged money condition ( $M=4.7317)$ have experienced more individual self-consciousness than those in the surprise-tagged money condition $(\mathrm{M}=3.3955)$ $(\mathrm{F}(1,83)=32.755, \mathrm{p}<.001)$. Therefore, $\mathrm{H1}$ was supported.

And one-way ANOVA to test $\mathrm{H} 2$ showed the money in the pride-tagged money condition $(M=5.122)$ is considered being more valuable than the money in the surprise-tagged money condition $(\mathrm{M}=4.0455)(\mathrm{F}(1,83)=7.497, \mathrm{p}<$ $.01)$. Therefore, H2 was supported.

To test H3, firstly, we carried out ANOVA to check whether participants in the pride-tagged money condition would like to save more money than those in the surprise-tagged money condition. Consistent with our prediction, participants in the pride-tagged money condition ( $\mathrm{M}=97.9268)$ would like to save more money than those in the surprise-tagged money condition $(M=62.6136)(F(1,83)=18.715, p<$ $.001)$. In addition, participants in the pride-tagged money condition ( $M=52.0732)$ would like to spend less money than those in the surprisetagged money condition ( $\mathrm{M}=87.3864)$ ( $\mathrm{F}(1$, $83)=18.715, \mathrm{p}(.001)$. Therefore, H3 was supported.

The results of one-way ANOVA to test H4 showed participants in the pride-tagged money condition ( $M=4.1073)$ were more likely to be motivated to express the individual self than those in the surprise-tagged money condition $(\mathrm{M}=2.6864) \quad(\mathrm{F}(1,83)=22.528, \mathrm{p}<.001)$, which is consistent with our prediction. Thus hypothesis 4 was supported.

In $\mathrm{H} 5 \mathrm{a}$, we predict that while receiving a sum of money can be added into their budget range for expenditure, people with surprise-tagged money are more likely to broaden the budget range than those people with pride-tagged money. The results of ANOVA to test H5a showed that participants in the pride-tagged money condition $(M=3.2276)$ set a narrower budget range for expenditure than those in the surprisetagged money condition ( $\mathrm{M}=4.8258)$ ( $\mathrm{F}(1$, 83) $=34.26, p<.001)$. Therefore, H5a was supported.

In addition, we computed the number of products participants listed on the questionnaire, which was used to measure consumers' variety seeking tendency. The results of one-way ANOVA showed that there was a significant difference of variety-seeking tendency between two conditions $(\mathrm{F}(1,83)=6.871, \mathrm{p}<.05)$; in particular, participants in the pride-tagged money condition $(\mathrm{M}=2.5366)$ listed fewer types of product than those in the surprise-tagged money condition $(\mathrm{M}=3.2727)$. Therefore, H5b was supported.

\subsubsection{Discussion}

In Study 1, we demonstrated that the differ- 
ent affective tags (pride and surprise) affixed to money trigger different types of consumer's judgments and responses toward the money (e.g., money's psychological value and mental budget range). However, we did not identify recipient's specific consumption behaviors after they received the money (pride-tagged and surprise-tagged money). Thus, in Study 2, we attempt to find out type difference of spending and consumption behaviors between consumers with pride-tagged money and consumers with surprise-tagged money.

\section{Pride-tagged and Surprise- tagged Money and Consumption Behaviors}

\subsection{Purchase Intention of Unaffordable Product in the Ordinary Consumption}

People treat money account as nonfungible; money in one account will not be spent in another (Thaler, 1985, 1999). Typically, a monthly salary is the additional funds placed in the current account and will be used immediately for the ordinary consumption, such as for rice and housing expense. However, when receiving a sum of extra money (e.g., win a lottery) unexpectedly, the majority of consumers tend to open a new mental account to buy some products that they want to own but could not af- ford at the expense of ordinary income.

Even though consumers have a strong tendency to set mental budgets linked to longterm-focused needs with priority they might group unexpectedly received money into current spendable income, which leads to an increase of the budget range for extra expenditure. With the broadening of budget range for the expenditure, it is natural for consumers to engage in the transactions that they had failed to fulfill in the ordinary consumption. Thus we predict both consumers with pride-tagged money and those with surprise-tagged money are likely to upper the limit of their original budget range for current spending and then purchase products that they would like to buy but could not afford in the past. Our hypothesis is expressed as follows:

H6: There will be no difference of intent to spend on unfulfilled transactions between consumers with pride-tagged money and consumers with surprise-tagged money.

\subsection{Effort-reward and Self-gifts}

Pride, relative to other feelings, involves increased self-awareness (Tracy and Robins, 2004). When people consider that a positive outcome (e.g., receiving a scholarship) is attributed to an internal cause (e.g., individual's hard-working) which often triggers feelings of pride, their sense of deservingness based on ability and/or 
effort should be high (Mick and DeMoss, 1990). Thus they might attempt to reward their invested individual effort. For instance, participants who have experienced success in an achievement task are more likely to indulge in self-gratification (Mischel et al., 1968) that is one of the significant motives for consumers' self-gift.

In contrast, a positive outcome attributed to an external cause (e.g., receiving a sum of money because of some uncontrollable factors, such as luck) may result in a reduced sense of deservingness and may decrease the probability of rewarding one's effort. Therefore, we hypothesize that people prefer buying personal gifts by using pride-tagged money rather than surprisetagged money. Our hypotheses are expressed as follows:

$\mathrm{H7}_{\mathrm{a}}$ : Consumers with pride-tagged money are more likely to engage in effort-reward than those with surprise-tagged money.

$\mathrm{H}_{b}$ : Consumers with pride-tagged money are more likely to engage in self-gifts than those with surprise-tagged money.

\subsection{Purchase of Individual Self-expressive and Social Self-expressive Products}

Consumers' identities reflect different facets of the self; it varies across time and context (Bhattacharjee, Berger, and Menon, 2014). People often use their various identities to socially categorize themselves and express who they are. Identity salience principle put forth by Reed II et al., (2012) suggests that the activation of a person's a specific identity varies as a function of the salience of his or her personal distinctiveness or relative rarity of personality traits. For example, when the female participants were placed in the groups that were different from their gender composition, the participants' gender identity is salient, and become more salient when females were a minority than they were a majority (Cota and Dion, 1986).

In a similar vein, feeling proud of oneself tends to promote perceptions of competency and thus increases the likelihood of expressing individuals' unsurpassed accomplishments. Since Study 1 has found that the receipt of a scholarship (pride-tagged money) could help participants see their individual self as the center of attention, we propose that the invested personal effort and the salience of self-importance can be considered as factors increasing the salience of individual self-identity within a person's selfconcept, which in turn, increases the likelihood of consumers performing behaviors consistent with the salient individual identity.

On the other hand, some social situations (e.g., the physical aspects or descriptions of the situation) or social surroundings (e.g., other people present in the situation) could lead to the accessibility of individuals' a specific set of personality traits (Reed II et al., 2012). Winning 
a lottery prize might make a person be motivated to care about the impressions they make on others and strive to protect their social image, which is triggered by the physical aspects of the situation (e.g., lottery station, prize, lottery ticket) and the social surroundings (e.g., other people who present in the lottery-win situation, such as family members, friends, and colleagues).

Individual self-expressive products are often viewed as uncongenial and non-default options that satisfy consumer's needs of uniquenessseeking, better express consumer's individual preferences, attitudes, and desires, and are chosen by minority of people. In contrast, social selfexpressive products can be viewed as conventional and default options that serve to satisfy consumer's conformity needs, are less likely to be criticized, and are chosen by majority of people (Maimaran and Simonson, 2011). Purchasing a social self-expressive option could reduce potential criticism, thus consumers with surprisetagged money might prefer social self-expressive products to those products linked to individual self-expression.

In support of this, Reed II et al. (2012) suggest that the identity-driven effect occurs through a simple associative transfer. When a particular identity within a person's self-concept is activated, the person tends to retrieve information related to the activated identity, which further influences subsequent attitudes and behaviors. Unlike the receipt of pride-tagged money that triggers the association linked to one's individual self-identity and further generates the behavior of purchasing products related to the activated individual self-identity, receiving surprise-tagged money might produce associations linked to individuals' multiple social identities, which further leads to preferences for various types of options. Our hypothesis is expressed as follows:

H8: When engaging in self-gifts, consumers with pride-tagged money show a bigger difference between the intent to buy individual self-expressive products and the intent to buy social self-expressive products than those with surprise-tagged money.

\section{Study 2:}

The purpose of Study 2 was two-fold. Firstly we want to confirm our prediction that participants with pride-tagged money are more motivated to express their individual self when purchasing products than those with surprisetagged money. Secondly, Study 2 aims to explore type difference of consumers' consumption and spending behaviors between pride-tagged money expenditure and surprise-tagged money expenditure. 


\subsection{Method and Procedure}

\subsubsection{Participants and Procedure}

We administered the main survey to 210 students from large university in Study 2 in exchange for a gift that costs $\$ 2$. We employed a questionnaire survey methodology for our data collection.

There are two sections in Study 2. In the first section, similar to Study 1, we assigned participants into two groups, 105 participants to each, and informed them to fill out a questionnaire with scenario different between pridetagged money $W 1,500,000$ condition and surprise-tagged money $W 1,500,000$ condition. On completion of reading the same scenario as used in Study 1, we informed participants in each condition to complete a survey used to measure their feelings about the money. Following the emotion measures, we told participants to complete emotion arousal measures designed to assess the degree to which participants felt arousal about the money. And we informed participants to complete self-expressive motive measures.

In the second section of the questionnaire, participants were told to answer the main survey of this study. Firstly, we informed participants in each condition to list all the products that they would like to buy but could not afford in the past life, and to indicate one option that they want to buy most, which was followed by a survey used to measure whether they would like to use the received money $\mathbb{W 1 , 5 0 0 , 0 0 0}$ (scholarship/lottery prize) to buy the product they want to buy most anchored by "not at all (1) - very much (7)".

Secondly, we referred to one item to measure whether participants would like to reward their invested individual effort after receiving the extra money (e.g., scholarship/lottery prize) anchored by "not at all (1) - very much (7)". And we used one item to measure participants' gift giving behavior. We told them to imagine if they would like to buy a gift by using the received money, which kind of gift-giving behavior would they engage in, the scale of which is anchored by "other gift (1) - self gift (7)".

Thirdly, we told participants in both conditions to read an instruction about needs of individual self-expression and told them to list all the products that they think can express their individual self and then to indicate one kind of product that can express their individual self most, which was followed by a survey used to measure purchase intention of individual selfexpressive product.

Fourthly, all the participants were told to read an instruction about needs of social selfexpression. And then we told them to list all the products that they think can express their social self and to indicate one option that they think can express their social self most, which was followed by a survey used to measure the purchase intention of social self-expressive product.

Finally, some demographic information was 
presented in the final section of the survey. All the participants were allowed as much time as they need to complete the questionnaire.

\subsection{Measures}

\subsubsection{Emotion Arousal}

We used four items to measure participants' emotion arousal in both pride-tagged money and surprise-tagged money condition anchored by "not at all (1) - very much (7)", including four arousal-related words: aroused, excited, activated, and elated (Fedorikhin and Patrick, 2010).

\subsubsection{Individual (Social) Self-Expressive Product Purchase Intention}

We referred to four items to measure consumer's individual (social) self-expressive product purchase intention anchored by "strongly disagree (1) - strongly agree (7)" (Bower, 2001; Dodds, Monroe, and Grewal, 1991). The items include "I intend to purchase individual (social) self-expressive product by using the received money," "I would like to purchase individual (social) self-expressive product by using the received money," "I would consider purchasing individual (social) self-expressive product by using the received money," and "There is a strong likelihood that I will purchase individual (social) selfexpressive product by using the received money".

\subsection{Results}

\subsubsection{Manipulation Check}

Similar to Study 1, in order to confirm the effectiveness of our affect manipulation, we carried out a one-way ANOVA. The affect index $(\mathrm{P}-\mathrm{S})$ calculated by the same way as used in Study 1, reveals that participants in the pride-tagged money condition reported the greater degree of pride about the received money ( $\mathrm{M}$ $=1.2921$ ) than participants in the surprisetagged money condition $(\mathrm{M}=-2.1968)(\mathrm{F}(1$, 208) $=263.340, \mathrm{p}(.001)$

Different from Study 1, in Study 2, we used total three items to measure the appraisal dimensions of pride and surprise that were used to distinguish pride from surprise on a sevenpoint scale $(1=$ good/ others or environmental factors luck/ uncertainty, $7=$ self/individual effort/ certainty). Consistent with our prediction, the results of MANOVA showed that there was a main effect of responsibility $(F(1,208)$ $=397.152, \mathrm{p}<.001)$ and effort $(\mathrm{F}(1,208)=$ 167.720, $\mathrm{p}<.001)$. In particular, participants in the pride-tagged money condition were more likely to consider their individual self per se and individual effort as responsible for receiving the money than those in the surprise-tagged money condition $\left(\mathrm{M}_{\mathrm{p} \text {-self }}=5.7143\right.$ vs. $\mathrm{M}_{\mathrm{s} \text {-self }}=1.7810$; $M_{\text {p-effort }}=5.6571$ vs. $\left.M_{s \text {-effort }}=2.7905\right)$. In other words, participants in the surprise-tagged money condition were more likely to consider luck and 
others as being responsible for receiving the money than those in the pride-tagged money condition. Moreover, participants in the pridetagged money condition $(\mathrm{M}=3.9333)$ felt more certain about receiving the money than those in the surprise-tagged money condition $(\mathrm{M}=$ 1.4476) $(\mathrm{F}(1,208)=199.330, \mathrm{p}<.001)$.

For the individual self-expressive motive manipulation check, as expected, we replicated our prediction that participants were more motivated to express the individual self when choosing products in exchange of pride-tagged money $(\mathrm{M}=4.8400)$ than in exchange of surprise-tagged money $(\mathrm{M}=3.1581)(\mathrm{F}(1,208)=101.584, \mathrm{p}<$ $.001)$.

\subsubsection{Construct Validity and Reliability}

We refined the measure and assessed each variable's convergent and discriminant validity by using the 210 sample. First, principal component analysis using the Varimax rotating method and Cronbach's alpha analysis were carried out to check whether all items of the questionnaire of each construct measured the expected concept. The results of the analyses are shown in 〈Table 2〉.

All items for each construct were highly loaded to the component concerned. The Cronbach's alpha values of all the constructs were over 0.8 , thus confirming the internal consistency among the measurement items. Items for each construct except purchase intention were summed and averaged.

\subsubsection{Results of Testing Hypotheses}

We carried out a one-way ANOVA to test H6. The results showed that both participants in the pride-tagged money condition $(\mathrm{M}=$ 5.8762) and those in the surprise-tagged money condition $(\mathrm{M}=6.1619)$ tended to purchase products that they would buy but could not afford in the past ordinary consumption after they received a sum of extra money $(F(1,208)$ $=2.242, \mathrm{p}>.05$ ), (See Figure 1). Therefore, H6 is supported.

One-way ANOVA to test H7a showed that participants in the pride-tagged money condition $(\mathrm{M}=5.9238)$ were more likely to reward their invested effort than those in the surprisetagged money condition ( $M=4.4762)(\mathrm{F}(1,208)$ $=59.349, \mathrm{p}<.001)$. Therefore, H7a was supported. Moreover, the results of another ANOVA showed that participants in the pride-tagged money condition $(M=5.0)$ were more likely to engage in self-gifts than those in the surprise-tagged money condition $(\mathrm{M}=4.5238)(\mathrm{F}(1,208)=4.343$, $\mathrm{p}<.05)$, which suggests that $\mathrm{H}_{\mathrm{b}}$ was supported (See Figure 1).

To test H8, firstly, we created an index of purchase intent difference (I-S) of two types of product (individual self-expressive and socialexpressive product) by subtracting the summed value of items for measuring social selfexpressive product purchase intention from the 
〈Table 2 > Reliability and Validity of Measurement Variable

\begin{tabular}{|c|c|c|c|c|c|c|c|}
\hline \multirow{2}{*}{ Construct } & \multirow{2}{*}{ Indicator } & \multicolumn{6}{|c|}{ Component } \\
\hline & & 1 & 2 & 3 & 4 & 5 & 6 \\
\hline \multirow{5}{*}{ Self-Expressive Motive } & ExpM 2 & .839 & -.019 & .021 & .211 & .184 & -.081 \\
\hline & ExpM 4 & .811 & .018 & .060 & .024 & .164 & .036 \\
\hline & ExpM 1 & .801 & .034 & .088 & .250 & .224 & .020 \\
\hline & ExpM 3 & .801 & -.011 & .044 & .308 & .138 & .080 \\
\hline & ExpM 5 & .737 & .018 & .021 & .004 & .359 & -.024 \\
\hline \multirow{4}{*}{$\begin{array}{c}\text { Social Self-Expressive product } \\
\text { Purchase Intention } \\
\text { (SEPI) }\end{array}$} & SEPI 2 & -.023 & .918 & .285 & .086 & .001 & .113 \\
\hline & SEPI 3 & .005 & .916 & .286 & .092 & .002 & .112 \\
\hline & SEPI 4 & -.010 & .908 & .288 & .107 & -.024 & .067 \\
\hline & SEPI 1 & .054 & .893 & .289 & .077 & -.002 & .089 \\
\hline \multirow{4}{*}{$\begin{array}{l}\text { Individual Self-Expressive } \\
\text { product Purchase Intention } \\
\text { (IEPI) }\end{array}$} & IEPI 3 & .061 & .258 & .906 & .063 & .028 & .006 \\
\hline & IEPI 4 & -.008 & .265 & .901 & .057 & .050 & .011 \\
\hline & IEPI 2 & .068 & .310 & .892 & .079 & .059 & -.011 \\
\hline & IEPI 1 & .114 & .286 & .872 & .108 & .032 & .074 \\
\hline \multirow{4}{*}{ Emotion Arousal } & Arousal 3 & .135 & .079 & .164 & .852 & .131 & .143 \\
\hline & Arousal 2 & .101 & .144 & .064 & .851 & .005 & .307 \\
\hline & Arousal 4 & .304 & .051 & .023 & .849 & .195 & .054 \\
\hline & Arousal 1 & .273 & .131 & .074 & .704 & .399 & -.025 \\
\hline \multirow{3}{*}{ Pride } & Pride 2 & .437 & -.025 & .072 & .228 & .830 & -.041 \\
\hline & Pride 1 & .434 & -.063 & .074 & .204 & .826 & .003 \\
\hline & Pride 3 & .461 & .039 & .031 & .227 & .776 & -.019 \\
\hline \multirow{3}{*}{ Surprise } & Surprise 2 & .049 & .139 & .058 & .192 & .043 & .899 \\
\hline & Surprise 1 & .069 & .039 & .029 & .150 & .115 & .883 \\
\hline & Surprise 3 & -.103 & .118 & -.021 & .030 & -.204 & .780 \\
\hline \multicolumn{2}{|l|}{ Eigenvalue } & 7.533 & 5.231 & 2.668 & 1.500 & 1.441 & .955 \\
\hline \multicolumn{2}{|l|}{$\%$ of Variance } & 32.754 & 22.745 & 11.601 & 6.523 & 6.265 & 4.153 \\
\hline \multicolumn{2}{|l|}{ Cumulative \% } & 32.754 & 55.499 & 67.099 & 73.622 & 79.887 & 84.040 \\
\hline \multicolumn{2}{|l|}{ Cronbach's $\alpha$} & .917 & .973 & .957 & .901 & .956 & .873 \\
\hline
\end{tabular}

summed value of items for measuring individual self-expressive product purchase intention; a higher score on this index reflected a greater difference between the two kinds of product purchase intention. Secondly, we carried out a one-way ANOVA to test H8. The analysis re- sults showed significant purchase intent difference between the two conditions $(F(1,208)=$ 4.269, $\mathrm{p}<.05)$. That is, the difference $(\mathrm{M}=$ .9429) between the intent to buy individual self-expressive product and the intent to buy social-expressive product in the pride-tagged 
〈Flgure 1〉 Effect of Pride-Tagged and Surprise-Tagged Money on Unfufilled Consumption/

Effort-Reward/ Self-Gifts

- Pride condition $\backsim$ Surprise condition

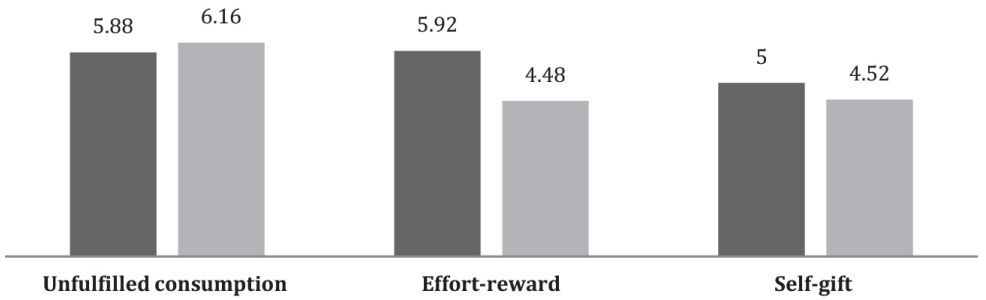

money condition was bigger than that $(\mathrm{M}=$ .5881) in the surprise-tagged money condition. Therefore, H8 was supported.

\subsubsection{Additional Analysis}

The results of Study 2 showed participants who experienced pride about money were more likely to choose individual self-expressive (vs. social self-expressive) product as a personal gift than those who experienced surprise. However, in Study 2, we found both participants with pride-tagged money and those with surprisetagged money $\left(M_{\text {pride }}=5.0\right.$ vs. $\left.M_{\text {surprise }}=4.5238\right)$ tended to buy a personal gift for themselves after receiving a sum of extra money even though the intent difference to purchase selfgift between two conditions was significant ( $F$ $(1,208)=4.343, \mathrm{p}<.05)$.

Past research has shown that arousal is a critical component of affect and its influences on individuals' decision-making can be in- dependent of the valence of an individual's affect or mood (Fedorikhin and Patrick, 2010; Gorn, Pham, and Sin, 2001), thus it is important to examine the effects of emotional states of the same valence at different levels of arousal on consumers' spending behaviors.

In order to additionally examine the effects, firstly, in the pride-tagged money condition, we summed and averaged the four items ( $\alpha=.908$ ) used to check the arousal level of pride manipulation, producing an arousal index of pride. The median score on this arousal index was 5.75; we categorized participants who scored above (below) this score as people with high (low) arousal of pride. Secondly, using the same method, we produced an arousal index of surprise $(\alpha=.902)$. The median score on this arousal index was 4.75; we categorized participants who scored above (below) this score as people with high (low) arousal of surprise.

Subsequently, we ran two way ANOVA by using types of feelings (pride and surprise) 
about the money and types of arousal as the independent variable and the purchase intent difference between two types of products (I-S) as the dependent variable. The analysis results showed that there was a main effect of types of feelings about the money $(F(1,206)=$ 4.475, $\mathrm{p}<.05)$, which is consistent with what we predicted in H8. However, there was no main effect of types of arousal on purchase intent difference of two types of product $(F(1$, 206) $=.83, \mathrm{p}>.05)$.

In addition, the interaction effect of types of feelings about the money and types of arousal on the purchase intent difference of two types of product was significant $(F(1,206)=9.404$, $\mathrm{p}<.01$ ). To illustrate, among participants in the pride-tagged money condition, there was no the purchase intent difference between participants with high pride arousal $(M=1.1226)$ and those with low pride arousal $(\mathrm{M}=.7596)$. Among participants in the surprise-tagged money condition, participants with high arousal of sur- prise $(M=.25)$ showed a smaller purchase intent difference between the two types of product than those with low arousal of surprise $(\mathrm{M}=.91)$, which is consistent with our prediction that people with high arousal of surprise tend to upper the limit of their expenditure budget range and thus increase the likelihood of purchasing both individual self-expressive and social self-expressive products. In short, affect arousal played a moderating role on the effects of types of feelings (pride and surprise) associated with the received money on the purchase intention difference (See Figure 2).

Additionally we analyzed the impacts of arousal level on the difference for each of pride-tagged money and surprise-tagged money. Regression analysis showed that there were significant (not significant) impacts of the arousal level on the difference under the condition of surprise (pride)-tagged money $(\beta=-2.00, \mathrm{t}=$ -2.076, $\mathrm{p}<.05(\beta=.011, \mathrm{t}=.110, \mathrm{p}>.05))$.

〈Flgure 2〉 The Moderating Role of Affect Arousal

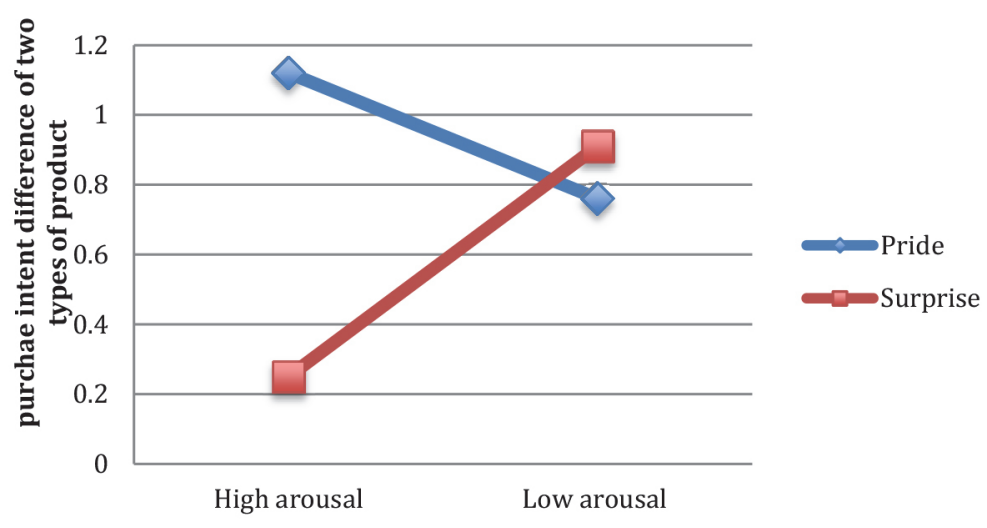




\subsubsection{Discussion}

In light of the findings of Study 2, we have explored, after receiving a sum of money, recipients who have experienced different feelings tend to engage in different spending or consumption behaviors, such that consumers with pride-tagged money are more likely to purchase products related to individual self-expression and to reward their invested effort. In short, there is a difference of spending behaviors in response to the receipt of a sum of money between consumers with pride-tagged money and consumers with surprise-tagged money. This evidence rests primarily on the logical notion that when receiving a sum of money associated with different feelings, consumers tend to set different budget range in their mind before spending the money.

\section{General Discussion}

\subsection{Implication to the Theory and Practice}

\subsubsection{Theoretical Implications}

Firstly, the current research differs from the past literatures on emotional accounting that focused on the valence of feelings (e.g., positive or negative feelings) rather than on the specific feelings. We contribute to theory de- velopment by exploring that the receipt of pridetagged money tends to activate motivation to express one's individual self, which, in turn, generates behaviors related to individual selfexpression.

Secondly, our current research contributes to theory on variety seeking by finding that consumers receiving a sum of extra money and adding the money into the current spendable income, tend to widen budget range for expenditure to broaden the array of product category they choose and seek a variety of different product items they desire.

Thirdly, our research further confirms the arguments that affect arousal, independent of the valence of one's affect, could strengthen the link between feelings and decisions by activating stronger appraisal tendencies and plays a significant role in consumer's decision-making process. When receiving a sum of unpredictable money because of good luck (surprise-tagged money), consumers with high level arousal of surprise show a smaller difference between the intent to buy individual self-expressive product and the intent to buy social self-expressive product than those with low level arousal in pride, which verifies the moderating role of affect arousal in affect regulation.

\subsubsection{Practical Implications}

In the current research, we found that people who have experienced feelings of pride (vs. 
surprise) about a sum of money are more motivated to express the individual self, as a result, are more likely to purchase products that help express individual self. We infer that such individual self-expressive products should be promoted on various mass media to draw attention of consumers who aim to express their individual self in view of their invested efforts and achievement.

The current environment could encourage consumers to express themselves and share what they have done and their lifestyle that they have managed. With the development of online social networking service (SNS), the majority of consumers, especially the young, tend to use various communication channels such as Facebook, Wechat, and Twitter, to create a personal profile, make friends, exchange messages, and upload and update photos. Consistent with our findings, we predict that consumers who have received a scholarship are more inclined to express their individual self and to show their preferences, attitudes and desires in their SNS than consumers who have won a lottery prize. Therefore, marketers or advertising developers who deliver product information in various social networking services should potentially develop and promote advertisements of products related to individual self-expression by using nontraditional colors that stand out (e.g., red and color) in product or logo design when attempting to induce consumers to select the individual self-expressive options.
Another practical contribution driven from our research relates to the consumers' willingness to a charitable donation. Donation is often viewed as a good way to close others, to protect one's social image, and to receive the approval of others in order to avoid criticism and rejection. When consumers have won a large sum of unpredicted money like lottery winning, they might be more aware that others can judge them on the basis of their consumption behaviors, as a result, are more likely to consider the welfare of others. We infer that consumers who have a strong and salient social self-identity are more likely to consider the welfare of others and offer benefits to others than those with a salient individual self-identity, presumably because developing an association with other people or groups can contribute to the one's social self- image. Thus social charity organizations should strive to develop some message that can activate one's social self-identity to attract people's attention to the donation. For example, using slogans such as "what kind of behavior is better to improve your self-importance and to advance your society where you have made your life?" might be appropriate to arouse consumers' desires to express their social self. Moreover, some promotion tactics, such as donation-based promotion can promote consumers' willingness to a charitable donation (Winterich and Barone, 2011).

It is important to note that although specific emotion can affect product choice, at the core 
of our finding is how marketers or advertisers use the specific emotion tagged to customers' money. One tricky question in the application of this research is how they can separate customers based on the specific emotion such as pride and surprise tagged to their money. Although market could be segmented based on various events that are highly correlated with the specific emotion, it is also possible that the specific emotion can be easily activated in the real world. For example, a psychological state of the specific emotion can be evoked by being accessed to social status transitions to validate his or her roles based on customers' invested efforts vs. others' supports, or customer's meeting with friends after making great achievement by his or her own efforts vs. by his or her own good luck, etc. Therefore advertisers can effectively use advertisement type for their customers to be immersed into the specific emotion by searching what kind of event they have experienced.

\subsection{Limitations and Directions for Future Research}

Many of the limitations of this research stem from the experimental context used to test our theory. The first limitation is related to the product choice. In this research, we had not chosen a specific product or brand as individual (social) self-expressive target. Instead, we told participants to list and indicate the products that they think can express their individual (social) self and then measure their purchase intention of the product that they think can express their individual (social) self most. Therefore, the future study should put emphasis on finding recipient's specific product or brand choice when they aim to express their individual self or social self.

Secondly, in this research, we told participants to image that they have received $\$ 1,500,000$ in both conditions (e.g., scholarship and lottery prize), however, we believe the amount of participants' received money should have an effect on participants' consumption behaviors. For example, some participants, might consider the

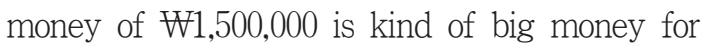
them, which could help engage in saving rather than spending behavior, regardless of whether the money is earned through individual's effort or not. Therefore, further research should consider the extent to which the money amount earned unexpectedly is valuable to the consumers.

Last but not the least, both studies in our article involved student participants. There could be some reasons why students' choices will differ significantly from other population's choices. Therefore, empirical investigations involving different demographics should be conducted in the future study.

〈Received March 18. 2015〉

〈Revised August 4. 2015〉

〈Accepted October 15. 2015〉 


\section{References}

Aaker, Jennifer L. (1999), "The Malleable Self: The Role of Self-Expression in Persuasion," Journal of Marketing Research, 36 (February), 355-362.

Aaker, Jennifer L. and Patti Williams (1998), "Empathy versus Pride: The Influence of Emotional Appeals across Cultures," Journal of Consumer Research, 25 (3), 241-261.

Arkes, Hal R. and Catherine Blumer (1985), "Psychology of Sunk Cost," Organizational Behavior and Human Decision Processes, 35 (1), 124-140.

Arkes, Hal R., Cynthia A. Joyner, Mark V. Pezzo, Jane Gradwohl Nash, Karen Siegel-Jacobs, and Eric Stone (1994), "The Psychology of Windfall Gains," Organizational Behavior and Human Decision Processes, 59 (September), 331-347.

Berger, Jonah and Chip Heath (2007), "Where Consumers Diverge from Others: Identity Signaling and Product Domains," Journal of Consumer Research, 34 (August), 121134.

Bhattacharjee, Amit, Jonah Berger, and Geeta Menon (2014), "When Identity Marketing Backfires: Consumer Agency in Identity Expression," Journal of Consumer Research, 41 (August), 294-309.

Bower, Amanda B. (2001), "Highly Attractive Models in Advertising and Women Who
Loathe Them: The Implementations of Negative Affect for Spokesperson Effectiveness," Journal of Advertising, 30 (3), 51-63.

Chernev, Alexander, Ryan Hamilton, and David Gal (2011), "Competing for Consumer Identity: Limits to Self-Expression and the Perils of Lifestyle Branding," Journal of Marketing, 75 (May), 66-82.

Cota, Albert A. and Kenneth L. Dion (1986), "Salience of Gender and Sex Composition of Ad Hoc Groups: An Experimental Test of Distinctiveness Theory," Journal of Personality and Social Psychology, 50 (4), 770-776.

Dodds, William B., Kent B. Monroe, and Dhruv Grewal (19991), "The Effects of Price, Brand, and Store Information on Buyers' Product Evaluation," Journal of Marketing Research, 28 (August), 307-319.

Epley, Nicholas and Ayelet Gneezy (2007), "The Framing of Financial Windfalls and Implications for Public Policy," Journal of Socio-Economics, 36 (1), 36-47.

Faure, Corinne and David Glen Mick (1993), "Self-Gifts Through the Lens of Attribution Theory," Advances in Consumer Research, 20 (1), 553-556.

Fedorikhin, Alexander and Vanessa M. Patrick (2010), "Positive Mood and Resistance to Temptation: The Interfering Influence of Elevated Arousal," Journal of Consumer Research, 37 (December), 698-711. 
Fenigstein, Allan, Michael F. Scheier, and Arnold H. Buss (1975), "Public and Private SelfConsciousness: Assessment and Theory," Journal of Consulting and Clinical Psychology, 43 (4), 331-337.

Frijda, Nico H. (2005), "Emotion Experience," Cognition and Emotion, 19 (June), 473-497. Gorn, Gerald, Michel Tuan Pham, and Leo Yatming Sin (2001), "When Arousal Influences Ad Evaluation and Valence Does Not (and Vice Versa)," Journal of Consumer Psychology, 11 (1), 43-55.

Goukens, Caroline, Siegfried Dewitte, and Luk Warlop (2009), "Me, Myself, and My Choices: The Influence of Private Self-Awareness on Choice," Journal of Consumer Research, 46 (October), 682-692.

Gourville, John T. and Dilip Soman (1998), "Payment Depreciation: the Behavioral Effects of Temporally Separating Payments From Consumption," Journal of Consumer Research, 25 (2), 160-174.

Han, Seunghee, Jennifer S. Lerner, and Dacher Keltner (2007), “Feelings and Consumer Decision Making: The Appraisal-Tendency Framework," Journal of Consumer Psychology, 17 (3), 158-168.

Heath, Chip and Jack B. Soll (1996), “Mental Budgeting and Consumer Decisions," Journal of Consumer Research, 23 (June), 40-52.

Henderson, W. Pamela and Robert A. Peterson (1992), "Mental Accounting and Categorization," Organizational Behavior and Human
Decision Processes, 51 (February), 92-117. Izard, Carroll E. (1977), Human Emotions, New York: Plenum Press.

Keltner, Dacher, Jonathan Haidt, and Michelle N. Shiota (2006), "Social Functionalism and the Evolution of Emotions," in Evolution and Social Psychology, ed. Mark Schaller, Douglas T. Kenrick, and Jeffry A. Simpson, New York: Psychology Press, 115-142.

Lazarus, Richard S. (1991), "Emotion and Adaptation," New York: Oxford University Press.

Lerner, Jennifer S. and Dacher Keltner (2000), "Beyond Valence: Toward a Model of Emotion-Specific Influences on Judgment and Choice," Cognition and Emotion, 14 (4), 473-493.

Levav, Jonathan and Peter A. Mcgraw (2009), "Emotional Accounting: How Feelings About Money Influence Consumer Choice," Journal of Marketing Research, 46 (February), 66-80.

Maimaran, Michal and Itamar Simonson (2011), "Multiple Routes to Self- Versus OtherExpression in Consumer Choice," Journal of Marketing Research, 48 (August), 755-766. McGraw, A. Peter, Philip E. Tetlock, and Orie V. Kristel (2003), "The Limits of Fungibility: Relational Schemata and the Value of Things," Journal of Consumer Research, 30 (September), 219-229.

Reisenzein, Rainer, Wulf-Uwe Meyer, and Achim Schützwohl (1996), "Reactions to Surprising 
Events: A Paradigm for Emotion Research," in Proceedings of the 9th conference of the International Society for Research on Emotions, 292-296.

Mick, David Glen and Michelle DeMoss (1990), "Self-Gifts: Phenomenological Insights from Four Contexts," Journal of Consumer Research, 17 (3), 322-332.

Mischel, Walter, Brian Coates, and Antonette Raskoff (1968), "Effects of Success and Failure on Self-Gratification," Journal of Personality and Social Psychology, 10 (4), 381-390.

O’Curry, Suzanne (1997), "Income Source Effects," working paper, Depaul University, Chicago, Illinois.

O'Curry, Suzanne and Michal Strahilevitz (2001), "Probability and Mode of Acquisition Effects on Choices Between Hedonic and Utilitarian Options," Marketing Letters, 12 (1), 37-49.

Park, Sehoon and Moon-Yong Kim (2005), “The Impact of Attribute Importance in the Effects of Option Framing on Choice: Budget Range and Justification as Moderators of Loss Aversion," Psychology and Marketing; 29 (10), 726-737.

Prelec, Drazen and George Loewenstein (1998), "The Red and the Black: Mental Accounting of Savings and Debt," Marketing Science, 17 (1), 4-28.

Raghunathan, Rajagopal and Michel Tuan Pham (1999), “All Negative Moods Are Not Equal:
Motivational Influences of Anxiety and Sadness in Decision Making," Organizational Behavior and Human Decision Processes, 79 (1), 56-77.

Reed II, Americus, Mark R. Forehand, Stefano Puntoni, and Luk Warlop (2012), "Identitybased Consumer Behavior," International Journal of Research in Marketing, 29 (4), 310-321.

Reisenzein, Rainer, Wulf-Uwe Meyer, and Achim Schützwohl (1996), "Reactions to Surprising Events: A Paradigm for Emotion Research," in Proceedings of the 9th conference of the International Society for Research on Emotions, N. Frijda, ed., Toronto: ISRE, 292-296.

Richins, Marsha L. (1997), "Measuring Emotions in the Consumption Experiences," Journal of Consumer Research, 24 (September), 127-146.

Shefrin, Hersh and Meir Statman (1985), "The Disposition to Sell Winners Too Early and Ride Losers Too Long," Journal of Finance, 40 (3), 777-790.

Shefrin, Hersh and Richard H. Thaler (1992), "Mental Accounting, Saving, and Self-Control," in Choice Over Time, George F. Loewenstein and Jon Elster, eds. New York: Russell Sage, 187-330.

Shim, Soyeon and Mary Ann Eastlick (1998), "The Hierarchical Influence of Personal Values on Mall Shopping Attitude and Behavior," Journal of Retailing, 74 (1), 
139-160.

Simonson (1990), "The Effect of Purchase

Quantity and Timing on Variety-Seeking Behavior," Journal of Marketing Research, 27 (May), 150-162.

Smith, Craig A. and Phoeb C. Ellsworth, (1985), "Patterns of Cognitive Appraisal in Emotion," Journal of Personality and Social Psychology, 48 (4), 813-838.

Thaler, Richard H. (1980), “Toward a Positive Theory of Consumer Choice," Journal of Economic Behavior and Organization, 1 (1), 39-60.

Thaler, Richard H. (1985), "Mental Accounting and Consumer Choice," Marketing Science, 4 (Summer), 119-214.

Thaler, Richard H. (1999), "Mental Accounting Matters," Journal of Behavioral Decision Making, 12 (September), 183-206.
Tracy, Jessica L. and Richard W. Robins (2004), "Putting the Self into Self-Conscious Emotions: A Theoretical Model," Psychological Inquiry, 15 (2), 103-125.

Weiss, Liad and Gita V. Johar (2013), "Egocentric Categorization and Product Judgment" Seeing Your Traits in What you Own (and Their Opposite in What you Don't)," Journal of Consumer Research, 40 (June), 185-201.

Wilcox, Keith, Thomas Kramer, and Sankar Sen (2011), "Indulgence or Self-Control: A Dual Process Model of the Effect of Incidental Pride on Indulgent Choice," Journal of Consumer Research, 38 (June), 151-163.

Winterich, Karen P. and Michael J. Barone (2011), “Warm Glow or Cold, Hard Cash? Social Identity Effects on Consumer Choice for Donation Versus Discount Promotions," Journal of Marketing Research, 48 (October), 855-868. 


\section{〈Appendix A〉 Scenario of This Research}

\section{For Pride-tagged Money:}

In the last semester, you actively took part in each specialized course of your major and made full preparations for both mid-term and final examinations. In return, you received a high GPA in the last semester. One day you received an e-mail from your college; it says that you have earned a scholarship

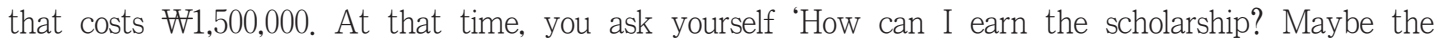
scholarship is benefited from my invested great efforts into study!' Now think about the feelings about the money you might have experienced in this situation.

For Surprise-tagged Money:

One day, on your way home, you came across a local lottery station and you bought a lottery ticket. A week later, when you were waiting for your friends in front of the school gate, you suddenly thought of the lottery ticket you bought last week. You entered the lottery station and found that you won a prize that costs $W 1,500,000$. At that time, you ask yourself 'How can I win the lottery prize? How lucky I am! It is indeed a windfall for me!' Now think about the feelings about the money you might have experienced in this situation.

\section{〈Appendix B〉 Individual and Social Self-Consciousness Scale (Fenigstein, Scheier, and Buss, 1975)}

\begin{tabular}{|c|c|}
\hline Individual self-consciousness & Social self-consciousness \\
\hline $\begin{array}{l}\text { 1. I'm always trying to figure myself out. } \\
\text { 2. Generally, I'm not very aware of myself. (-) } \\
\text { 3. I reflect about myself a lot. } \\
\text { 4. I'm often the subject of my own fantasies. } \\
\text { 5. I never scrutinize myself. (-) } \\
\text { 6. I'm generally attentive to my inner feelings. } \\
\text { 7. I'm constantly examining my motives. } \\
\text { 8. I sometimes have the feeling that I'm off } \\
\text { somewhere watching myself. } \\
\text { 9. I'm alert to changes in my mood. } \\
\text { 10. I'm aware of the way my mind works when } \\
\text { I work through a problem. }\end{array}$ & $\begin{array}{l}\text { 1. I'm concerned about my style of doing things. } \\
\text { 2. I'm concerned about the way I present myself. } \\
\text { 3. I'm self-conscious about the way I look. } \\
\text { 4. I usually worry about making a good impression. } \\
\text { 5. One of the last things I do before I leave my } \\
\text { house is look in the mirror. } \\
\text { 6. I'm concerned about what other people think of } \\
\text { me. } \\
\text { 7. I'm usually aware of my appearance. }\end{array}$ \\
\hline
\end{tabular}

